\title{
The role of neurological involvement in malignant tissues: architecture deterioration as a new medical hypothesis explaining cancer progression
}

\begin{abstract}
In this study, we reported our previous observations and perceptions regarding the involvement of neurological components in the malignant tissues. We used to examine different tissues with malignancy, and we observed increased involvement of neurological components as peripheral nerves. At the beginning, no plausible explanation to such phenomenon. Later, we showed in diabetic rat model that white matter was involved in diabetic progression through the up-regulation of inducible nitric oxide synthase (iNOS) and the down-regulation of heat shock protein70 (HSP70). We extended our investigations in other organs in the same model including kidney, liver, testes, and prostate. We found the same phenomenon of the expression of iNOS and HSP70 in the tissues of these organs. We also observed that there was a deterioration of tissue architecture due to diabetic effects. We think that this deterioration may result from the neurological involvement in these tissues. However, because diabetes may result in initiation of some tumors such as endometrium cancer, deterioration of tissue architecture and neurological involvement are becoming more importantly. This study aimed to introduce our hypothesis in this issue "Architecture deterioration as a new medical hypothesis explaining cancer progression". We also reviewed the relevant literature.
\end{abstract}

Keywords: tissue, architecture, deterioration, diabetes, malignancy, cancer progression
Volume II Issue 3 - 202 I

\author{
Ahed J Alkhatib ${ }^{1,2}$ \\ 'Department of Legal Medicine,Toxicology and Forensic \\ Medicine, Jordan University of Science \& Technology, Jordan \\ International Mariinskaya Academy, Department of medicine \\ and critical care, philosophy,Academician secretary of \\ department of Sociology, Jordan
}

Correspondence: Ahed J Alkhatib, Department of Legal Medicine, Toxicology and Forensic Medicine, Jordan University of Science \& Technology, Jordan, Tel 00962795905 I 45, Email ajalkhatib@just.edu.jo

Received: December 27, 2020 | Published: May 07, 2021

\section{Introduction}

Architecture of tissues vary from normal physiological status to malignant status. ${ }^{1}$ Architecture of a tissue is designed to serve both structure and function of the tissue. Tissue can be viewed as groups of cells that have shared properties including both structure and function. Furthermore, variations in structures of tissues are due to variations in their function. Extracellular matrix is considered as a medium by which tissue cells are retained. ${ }^{2}$

Tissues need blood supplying system for their nutrition, oxygenation and removing waste products. ${ }^{3}$ Tissues are also in need for nervous involvement for controlling their various activities, this mechanism is called nerve innervation. ${ }^{4}$

Several studies have reported that the nervous system has efficient role in the initiation and development of cancers. These studies demonstrate that the removal of certain nerves impedes tumor development. Moreover, tumors are more likely to have nerves than their original normal tissues. Large basic questions were asked in regard of tumor innervation since their formation and roles in disease progression. ${ }^{4}$

Through neural circuitry, brain can be in touch with all parts of the body. Studies showed that the development of normal neuron can be subjected to changes under the influences of diseases such as cancers. Early studies that reported the presence of nerves in tumors considered their presence as a part of the tumor microenvironment (TME). ${ }^{5,6}$ Further, the tumor innervation has become an important concept following the considerations that cancer cells communicate with nerves in tumor tissue intentionally.,

Ayala et al. ${ }^{9}$ showed that mouse cancer model of prostate revealed that neural processes stimulated the growth of cancer cells. In another study, Magnon et al. ${ }^{10}$ answered the question that what is it expected for prostate tumors in the case of absence of nerves? The study found that the ablation of nerves in prostate tumors impacted carcinogenesis in vivo. Later, researchers found that the ablation of nerves in both breast and gastric cancers impacted the growth of both cancers. ${ }^{11,12}$

\section{Deterioration of tissue architecture and tissue innervations}

Our previous studies showed that diabetic rat models exhibited deterioration of tissue architecture in different tissues. We have recently found that there was a deterioration in the glandular tissues of testis as a result of diabetes. ${ }^{13}$ This was considered as an adverse effect of diabetes. We also found that tissue architecture was not well preserved in liver tissue and endometrium tissue in diabetic rat models. ${ }^{14,15}$ In previous studies, we showed that white matter is involved in diabetes progression through the up-regulation of iNOS and down-regulation of HSP70. We concluded that brain may have a role in initiating diseases. ${ }^{16-18}$

\section{Study hypothesis}

From the previous context, we set up the following hypothesis: "The role of neurological involvement in malignant tissues: architecture deterioration as a new medical hypothesis explaining cancer progression". Our hypothesis implied that various pathologic conditions from diabetes to malignancies are associated with tissue deterioration and nerve innervation is postulated to be responsible for tissue deterioration and further disease progression. We have previously showed that disease progression depends on the downregulation of HSP70 and the up-regulation of iNOS, and if these mechanisms are reversed, disease may gradually disappear. We think that further studies are required to confirm our results. 


\section{Acknowledgments}

None.

\section{Conflicts of interest}

The authors declare no conflicts of interest.

\section{Funding}

None.

\section{References}

1. https://revistapesquisa.fapesp.br/en/the-architecture-of-tissues.

2. http://www.sc.chula.ac.th/courseware/2303101j/XI-Tissue.pdf

3. Jeroen Rouwkema, Bart FJM Koopman, Clemens A Van Blitterswijk, et al. Supply of Nutrients to Cells in Engineered Tissues. Biotechnology and Genetic Engineering Reviews. 2009;26:163-178.

4. Hunter D Reavis, H Isaac Chen, Ronny Drapki. Tumor Innervation: Cancer Has Some Nerve. Trends in Cancer. 2020;6(12):1059-1067.

5. Young HH. On the presence of nerves in tumors and of other structures in them as revealed by a modification of Ehrlich's method of "vital staining" with methylene blue. J Exp Med. 1897;2:1-12

6. Oertel H. Innervation and tumour growth: a preliminary report. Can Med Assoc J. 1928;18:135-139.

7. Servick K. War of nerves. Science. 2019;365:1071-1073.

8. Vermeer PD. Exosomal induction of tumor innervation. Cancer Res. 2019;79(14):3529-3535.

9. GE Ayala, T M Wheeler, H D Shine, et al. In vitro dorsal root ganglia and human prostate cell line interaction: redefining perineural invasion in prostate cancer. Prostate. 2001;49:213-223.
10. Claire Magnon, Simon J Hall, Juan Lin, et al. Autonomic nerve development contributes to prostate cancer progression. Science. 2013;341:1236361.

11. Chun-Mei Zhao, Yoku Hayakawa, Yosuke Kodama, et al. Denervation suppresses gastric tumorigenesis. Sci Transl Med. 2014;6:250ra115.

12. Kamiya A, Hyaman Y, Kato S, et al. Genetic manipulation of autonomic nerve fiber innervation and activity and its effect on breast cancer progression. Nat Neurosci. 2019;22:1289-1305.

13. Ali Alsarhan, Kawther Faisal Amawi, Inas Saleh Al-Mazari, et al. The Compound Expression of HSP90 and INOS in the Testis of Diabetic Rats as Cellular and Pathologic Adverse Effects of Diabetes. Analytical Cellular Pathology Volume 2020:3906583.

14. Muhammed Al-Jarrah, Ismail Matalka, Hasan Al Aseri, et al. Exercise Training Prevents Endometrial Hyperplasia and Biomarkers for Endometrial Cancer in Rat Model of Type 1 Diabetes. J Clin Med Res. 2010;2(5):207-214.

15. Kawther Faisal Amawi, Inas Saleh Al-Mazari, Ali Alsarhan, et al. Diabetes upregulates the expression of HSP90 and downregulates HSP70 in the liver of diabetic rats. Comparative Clinical Pathology. 2019;28(2):473478.

16. Ahed Al-Khatib. Co-expression of iNOS and HSP70 in diabetes type 1 makes a rational hypothesis to explain the diabetic neuropathy. European Journal of Scientific Research. 2013;9(3):1857-7881.

17. Ahed J Alkhatib. White Matter and Disease: Does Brain have a Role in Initiating Diseases. Brain Disorders \& Therapy. 2017;6:e124.

18. Ahed J Alkhatib. The Progression of a Disease Depends on Downregulation of Heat Shock Protein 70 (HSP70) And Upregulation of Inducible Nitric Oxide Synthase (iNOS): A New Medical Hypothesis. Biomed Discoveries. 2019;1-3. 